\title{
Induction of capacitation and the acrosome reaction of boar spermatozoa by L-arginine and nitric oxide synthesis associated with the anion transport system
}

\author{
H. Funahashi \\ Department of Animal Science, Okayama University, 1-1-1 Tsushima-naka, \\ Okayama 700-8530, Japan
}

\begin{abstract}
The aim of this study was to determine the effect of L-arginine on nitric oxide (NO) synthesis, capacitation and acrosome reaction of boar spermatozoa. Ejaculated boar spermatozoa were washed and then cultured in a bicarbonate: $\mathrm{CO}_{2}$-buffered medium, modified NCSU-37, for $2 \mathbf{h}$. At the end of the culture, the status of spermatozoa was determined. The presence of $\left(0.1-2.0 \mathrm{mmol} \mathrm{l}^{-1}\right)$ L-arginine in the culture medium induced an acrosome reaction as determined by fluorescein isothiocyanatepeanut agglutinin (FITC-PNA) and increased intracellular NO content, as quantified by a fluorescent indicator, diaminofluorescein-2 diacetate (DAF-2 DA). This stimulatory effect of L-arginine was neutralized by supplementation with an NO synthase inhibitor, $\mathrm{N}^{\omega}$-nitro-L-arginine methyl ester $\left(1 \mathrm{mmol}^{-1}\right)$. However, the inactive enantiomorph, $\mathrm{N}^{\omega}{ }^{\omega}$-nitro-D-arginine methyl ester, did not affect the
\end{abstract}

stimulatory effect of L-arginine. These results indicate that L-arginine induces an acrosome reaction through the NO signal pathway in boar spermatozoa. Furthermore, the stimulatory effect of L-arginine was inhibited in the presence of an anion transport inhibitor, 4-acetamido-4'-isothiocyanostilbene-2,2'-disulphonic acid (SITS; $0.1 \mathrm{mmol}^{-1}$ ), whereas any responses of spermatozoa to caffeine were not inhibited by SITS. A stimulatory effect of L-arginine on capacitation and acrosome reaction of spermatozoa was also observed in modified NCSU37 medium by using a chlortetracycline fluorescence assay, but not in supplemented bicarbonatefree Tris-buffered medium. These results indicate that the presence of L-arginine induces nitric oxide synthesis and stimulates capacitation and acrosome reaction of boar spermatozoa only when active sperm anion transport is present as a result of bicarbonate supplementation.

\section{Introduction}

Nitric oxide (NO) is a short-lived free radical synthesized by a class of NO synthases (NOS) that are responsible for the conversion of L-arginine to L-citrulline and $\mathrm{NO}$ (Palmer et al., 1988; Palmer and Moncada, 1989). NO appears to be involved not only in the function of the male genitourinary system (Burnett et al., 1992, 1995), but also in sperm physiology, such as hyperactivation, capacitation and acrosome reaction (de Lamirande et al., 1997). The presence of NOS has been observed in the acrosome and tail of mouse (Herrero et al., 1996, 1997a) and human spermatozoa (Herrero et al., 1996; Lewis et al., 1996). The NO-releasing compounds induce acrosome reaction in human (Herrero et al., 1999) and rabbit spermatozoa (Guzman-Grenfell et al., 1999). These data indicate that NO can be generated by spermatozoa and may regulate sperm function. As it is known that a NOS inhibitor $\mathrm{N}^{\omega}{ }^{\omega}$-nitro-L-arginine methyl ester (L-NAME), but not the inactive enantiomorph $\mathrm{N}^{\omega}$-nitro-D-arginine methyl ester (D-NAME), produces a dose-dependent inhibition of spontaneous and progesteroneinduced acrosome exocytosis of mouse spermatozoa in vitro (Viggiano et al., 1996; Herrero et al., 1997b), sperm

Email: hirofun@cc.okayama-u.ac.jp
NOS appears to participate in the acrosome reaction. Relatively high concentrations $\left(0.01-1.0 \mathrm{mmol} \mathrm{I}^{-1}\right)$ of sodium nitroprusside, a NO donor, inhibit motility and viability of human spermatozoa, but low concentrations (10-100 nmol $\mathrm{I}^{-1}$ ) result in increased capacitation without an effect on motility (Sengoku et al., 1998). Joo et al. (1999) demonstrated that sodium nitroprusside reduces both sperm motility and hyperactivation at $0.1-1.0 \mathrm{mmol} \mathrm{I}^{-1}$, but increases the percentage of acrosome-reacted human spermatozoa at 0.01-1.0 mmol $\mathrm{I}^{-1}$. NOS activity stimulated by follicular fluid proteins also increases the percentage of acrosome-reacted human spermatozoa (Revelli et al., 1999). Although a similar role of NO may be expected in boar spermatozoa, present information is limited to a few species, such as mice and humans. Supplementation with L-arginine stimulates the motility of rabbit (Randany and Atherton, 1981) and human spermatozoa in vitro (Keller and Polakoski, 1975). Therefore, L-arginine as a resource of NO may induce capacitation and acrosome reaction through the NO signal pathway. However, little is known about the effect of L-arginine and $\mathrm{NO}$ on boar spermatozoa.

Furthermore, it has been shown that bicarbonate is a key inducer of capacitation and penetration of boar spermatozoa in vitro (Suzuki et al., 1994; Harrison, 1996; Harrison et al., 1996). Bicarbonate induces protein kinase A-dependent 
Table 1. Composition of mNCSU37 and mTBM media

\begin{tabular}{lcc}
\hline Compound & $\mathrm{mNCSU} 37\left(\mathrm{mmol} \mathrm{I}^{-1}\right)$ & $\mathrm{mTBM}\left(\mathrm{mmol} \mathrm{I}^{-1}\right)$ \\
\hline $\mathrm{NaCl}$ & 108.73 & 113.1 \\
$\mathrm{NaHCO}$ & 25.07 & - \\
$\mathrm{KCl}$ & 4.78 & - \\
$\mathrm{KH}_{2} \mathrm{PO}_{4}$ & 1.19 & - \\
$\mathrm{MgSO}_{4} \cdot 7 \mathrm{H}_{2} \mathrm{O}$ & 1.19 & 7.5 \\
$\mathrm{CaCl}_{2} \cdot 2 \mathrm{H}_{2} \mathrm{O}$ & 1.70 & 20.0 \\
Tris & - & 11.0 \\
Glucose & 5.55 & 5.0 \\
Sodium pyruvate & 0.91 & - \\
Glutamine & 1.00 & - \\
Sorbitol & 12.00 & - \\
Insulin (mg l-1) & 5 & 25 \\
Gentamicin $(\mathrm{mg} \mathrm{l-1})$ & 25 & $0.4 \%$ \\
BSA (Sigma A7888) $(\mathrm{w} / \mathrm{v})$ & $0.4 \%$ & \\
\hline
\end{tabular}

mNCSU37: modified North Carolina State University medium 37 supplemented with 0.91 mmol sodium pyruvate I $^{-1}$; mTBM: modified Tris-buffered medium.

changes in the plasma membrane of boar spermatozoa (Gadella and Harrison, 2000). An anion transport inhibitor, such as 4-acetamido-4' -isothiocyanostilbene-2,2' -disulphonic acid (SITS), reversibly inhibits the bicarbonatesensitive adenylyl cyclase in the plasma membrane of boar spermatozoa (Okamura et al., 1991). Successful in vitro fertilization has been achieved not only in bicarbonate$\mathrm{CO}_{2}$-buffered media, such as Medium-199 (which originally contains L-arginine at $0.33 \mathrm{mmol} \mathrm{I}^{-1}$ ), but also in the supplement of bicarbonate-free Tris-buffered medium (for reviews, see Funahashi and Day, 1997; Abeydeera, 2001). It would be interesting to clarify whether L-arginine or NO is associated with a modification of anion transporters, such as the $\mathrm{HCO}_{3}{ }^{-}-\mathrm{Cl}^{-}$exchanger, in the induction of capacitation of boar spermatozoa.

The present study was undertaken to determine whether the addition of L-arginine affected NO synthesis and consequently induced the capacitation and acrosome reaction of boar spermatozoa, and whether the induction of capacitation and the acrosome reaction by L-arginine is associated with anion transporters.

\section{Materials and Methods}

\section{Materials}

$\mathrm{KCl}, \mathrm{KH}_{2} \mathrm{PO}_{4}, \mathrm{NaH}_{2} \mathrm{PO}_{4}, \mathrm{MgCl}_{2} \cdot 6 \mathrm{H}_{2} \mathrm{O}, \mathrm{MgSO}_{4} \cdot 7 \mathrm{H}_{2} \mathrm{O}$, $\mathrm{CaCl}_{2} \cdot 2 \mathrm{H}_{2} \mathrm{O}$, sodium citrate $2 \mathrm{H}_{2} \mathrm{O}$ and citric acid were purchased from Ishizu Pharmaceutical Co., Ltd (Osaka). $\mathrm{NaCl}$ and diaminofluorescein-2 diacetate (DAF-2 DA) were obtained from Nacalai Tesque Inc. (Kyoto) and Daiichi Pure Chemicals Co., Ltd (Kyoto), respectively. Other chemicals were purchased from Sigma Aldrich Japan K K (Tokyo).

\section{Culture media}

The basic medium for the incubation of spermatozoa was a modified North Carolina State University medium 37 supplemented with $0.91 \mathrm{mmol}$ sodium pyruvate $\mathrm{I}^{-1}$ (mNCSU37; Table 1). Modified Tris-buffered medium (mTBM; Table 1) was also used for sperm culture. The culture media were equilibrated in an atmosphere of $5 \%$ $\mathrm{CO}_{2}$ in air at $39^{\circ} \mathrm{C}$ for $>16 \mathrm{~h}$ before the start of incubation to obtain a $\mathrm{pH}$ of 7.2-7.4. The medium used for washing ejaculated spermatozoa was modified Tyrode's lactateHepes-polyvinyl alcohol (TL-Hepes-PVA) medium (Funahashi et al., 1997).

L-Arginine, L-NAME, D-NAME, SITS and caffeine were prepared as stock solutions of $0.1 \mathrm{~mol} \mathrm{I}^{-1}$ and stored at $-30^{\circ} \mathrm{C}$. For use, stock solutions were thawed and diluted with medium as required.

\section{Preparation of boar spermatozoa}

Sperm-rich fractions $(30-45 \mathrm{ml})$ were collected from seven Berkshire boars by the gloved hand method at a local livestock centre and were diluted four times with a modified Modena solution $\left(152.6 \mathrm{mmol}\right.$ trehalose $\mathrm{I}^{-1}, 23.5 \mathrm{mmol}$ sodium citrate $2 \mathrm{H}_{2} \mathrm{O} \mathrm{I}^{-1}, 11.9 \mathrm{mmol} \mathrm{NaHCO}_{3} \mathrm{I}^{-1}, 6.3 \mathrm{mmol}$ EDTA-2 $\mathrm{Na} \mathrm{I}^{-1}, 46.7 \mathrm{mmol}$ Tris $\mathrm{I}^{-1}, 15.1 \mathrm{mmol}^{-1}$ citric acid $\mathrm{I}^{-1}$, $5.0 \mathrm{mmol}$ cysteine $\mathrm{I}^{-1}$ and $10.0 \mathrm{mg}$ gentamycin $\mathrm{ml}^{-1}$ ). The diluted semen samples were transported to the laboratory within $2 \mathrm{~h}$ of collection and used immediately. Seminal plasma was removed by washing $5 \mathrm{ml}$ of diluted semen and mixing three times with TL-Hepes-PVA by centrifugation at $750 \mathrm{~g}$ for $3 \mathrm{~min}$. After washing, the pellets containing spermatozoa were resuspended to a concentration of $1 \times 10^{6}$ cells $\mathrm{ml}^{-1}$ in $\mathrm{mNCSU} 37$ or $\operatorname{mTBM}(2 \mathrm{ml})$ with or without supplemented L-arginine, L-NAME, D-NAME, caffeine or SITS.

\section{Acrosomal status of spermatozoa}

Acrosomal status of live spermatozoa was monitored by means of fluorescein isothiocyanate-conjugated peanut agglutinin (FITC-PNA) under an epifluorescent microscope 
(Fazeli et al., 1997). Sperm suspension (1 ml) was exposed to FITC-PNA $\left(10 \mu \mathrm{g} \mathrm{ml}^{-1}\right)$ and propidium iodide (PI, $12 \mu \mathrm{mol} \mathrm{I}^{-1}$ ) for $5 \mathrm{~min}$ at $39^{\circ} \mathrm{C}$ and then immobilized by adding $1 \mu \mathrm{l}$ of $12.5 \%(\mathrm{w} / \mathrm{v})$ paraformaldehyde on $0.5 \mathrm{~mol}$ Tris $\mathrm{I}^{-1}$ ( $\mathrm{pH}$ 7.4). Slides were prepared by placing $5 \mu \mathrm{l}$ of the sperm suspension on to a glass slide and adding a coverslip. Two hundred spermatozoa of each specimen were examined immediately under a phase-contrast microscope ( $\times 1000)$ equipped with epifluorescent optics to assess the proportion of live and dead spermatozoa, and acrosomal status. Spermatozoa stained with PI were considered as dead cells; spermatozoa stained with FITC-PNA but without PI were classified as live acrosome-reacted cells and spermatozoa without any fluorescence were considered as acrosome-intact live cells.

\section{Detection and quantification of NO synthesis}

NO synthesis from spermatozoa was detected and quantified by using an NO detection reagent, DAF-2 DA. After washing, spermatozoa were resuspended to a concentration of $1 \times 10^{8}$ cells $\mathrm{ml}^{-1}$ in TL-Hepes-PVA. DAF-2 DA was added to the suspension at a final concentration of $10 \mu \mathrm{mol}$ $\mathrm{I}^{-1}$ and incubated in air at $37^{\circ} \mathrm{C}$ for $1 \mathrm{~h}$. After centrifugation at $750 \mathrm{~g}$ for $3 \mathrm{~min}$, spermatozoa were resuspended to a concentration of $1 \times 10^{6}$ cells $\mathrm{ml}^{-1}$ in $\mathrm{mNCSU}-37$ with or without the addition of L-arginine and then cultured in an atmosphere of $5 \% \mathrm{CO}_{2}$ in air at $39^{\circ} \mathrm{C}$. For detection of $\mathrm{NO}$, slides were prepared by placing $5 \mu$ l of the sperm suspension on to a poly-L-lysine-coated glass slide and adding a coverslip. Emission fluorescence at $522 \mathrm{~nm}$ from spermatozoa was observed by using a laser scanning confocal imaging system (MRC-1024: Nippon Bio-Rad Laboratories, Tokyo). The fluorescent image was stored as a PIC file, and $\mathrm{NO}$ in a sperm head was quantified according to the pixel density of fluorescence determined with a standard MRC1024 program, LaserSharp (Nippon Bio-Rad Laboratories, Tokyo).

\section{Chlortetracycline fluorescence assessment of spermatozoa}

The methods used for chlortetracycline (CTC) analysis were performed according to Wang et al. (1995) with a few minor modifications as described previously (Funahashi et al., 2000; Funahashi and Nagai, 2001). Treated spermatozoa were assessed immediately under a phase-contrast microscope, equipped with epifluorescent optics. Each cell was first observed under UV illumination to determine whether it was alive or dead; the sperm cells showing bright blue staining of the nucleus (bis-benzimide Hoechst 33258positive cells) were considered as dead. One hundred live spermatozoa were examined under blue-violet illumination and classified according to CTC staining patterns. The three fluorescent staining patterns identified were: F: with uniform fluorescence over the whole sperm head; $B$ : with a fluorescence-free band in the post-acrosome region; AR: with almost no fluorescence over the sperm head except for a thin band of fluorescence in the equatorial segment (Wang et al., 1995).

\section{Experimental design}

Primarily, the effect of L-arginine on acrosome reaction was determined by resuspending spermatozoa in $2 \mathrm{ml}$ of $\mathrm{mNCSU}-37$ containing various concentrations $(0,0.01$, $0.05,0.1,0.5,1.0$ and $2.0 \mathrm{mmol} \mathrm{I}^{-1}$ ) of L-arginine and culturing for $2 \mathrm{~h}$ in an atmosphere of $5 \% \mathrm{CO}_{2}$ in air at $39^{\circ} \mathrm{C}$. The response of boar spermatozoa to L-arginine was assessed by means of FITC-PNA and PI staining.

Secondly, fluorescence from DAF-2 DA, a NO indicator, was quantified using a confocal microscope system at 0,30 and 60 min after adding various concentrations (0, 1.0 and $2.0 \mathrm{mmol} \mathrm{I}^{-1}$ ) of L-arginine to determine whether the effect of L-arginine was due to NO synthesis. The effect of L-arginine through the $\mathrm{NO}$ signal pathway was confirmed by culturing spermatozoa in mNCSU-37 without or with

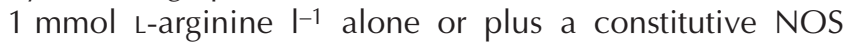
(cNOS) inhibitor L-NAME $\left(0.5,1.0\right.$ and $\left.2.0 \mathrm{mmol} \mathrm{I}^{-1}\right)$ or the inactive enantiomorph D-NAME $\left(1 \mathrm{mmol} \mathrm{I}^{-1}\right)$ for $2 \mathrm{~h}$. After culture, the response to L-arginine and L-NAME (or D-NAME) on boar spermatozoa was determined by means of FITC-PNA and PI staining.

Finally, to clarify whether the stimulatory effect of L-arginine is associated with the anion exchanger activity, the effect of $1 \mathrm{mmol} \mathrm{L}_{\text {-arginine }} \mathrm{I}^{-1}$ in the absence or presence of $0.1 \mathrm{mmol} \mathrm{SITS} \mathrm{I}^{-1}$ (an anion transport inhibitor) was compared with that of $1 \mathrm{mmol}$ caffeine $\mathrm{I}^{-1}$ or no additives by chlortetracycline fluorescence assay. Furthermore, spermatozoa were resuspended to $2 \mathrm{ml} \mathrm{mNCSU37}$ (which is a bicarbonate-buffered medium) or mTBM (which is a supplemented bicarbonate-free Tris-buffered medium) either without or with L-arginine alone $\left(0.5\right.$ and $\left.1.0 \mathrm{mmol} \mathrm{I}^{-1}\right)$ or in combination with $1 \mathrm{mmol}$ L-NAME $\mathrm{I}^{-1}$, cultured for $2 \mathrm{~h}$ in an atmosphere of $5 \% \mathrm{CO}_{2}$ in air at $39^{\circ} \mathrm{C}$, and then assessed by FITC-PNA and PI staining and chlortetracycline fluorescence assay, to confirm the importance of exogenous bicarbonate ions for the effect of L-arginine

\section{Statistical analyses}

Statistical analyses of the results from three to seven replicated experiments were used for treatment comparisons and were carried out by one-way ANOVA using the STATVIEW (Abacus Concepts, Inc., Berkeley, CA) program. If significance was $P<0.05$ in ANOVA, Fisher's protected least significant difference test was followed using the STATVIEW (Abacus Concepts, Inc., Berkeley, CA) program. All percentage data were subjected to arc-sine transformation before statistical analysis. For showing percentage data in figures, data were transformed back to the original percentages and are expressed as mean percentage with ranges. All other data are expressed as mean \pm SEM. $P \leqslant 0.05$ was considered to be significant. 


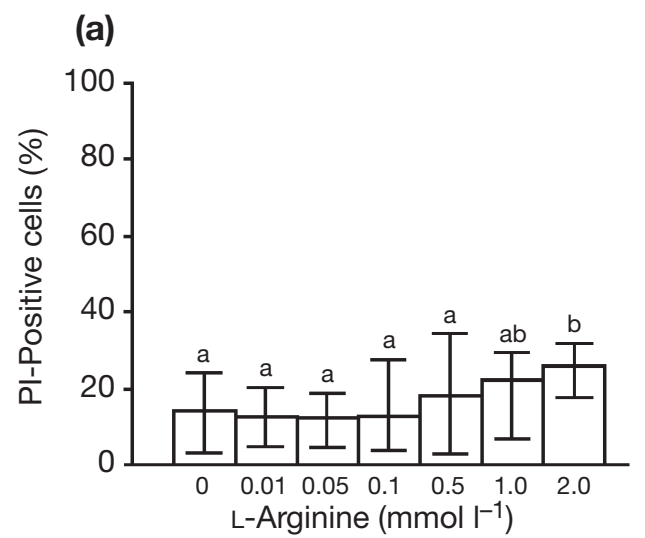

(b)

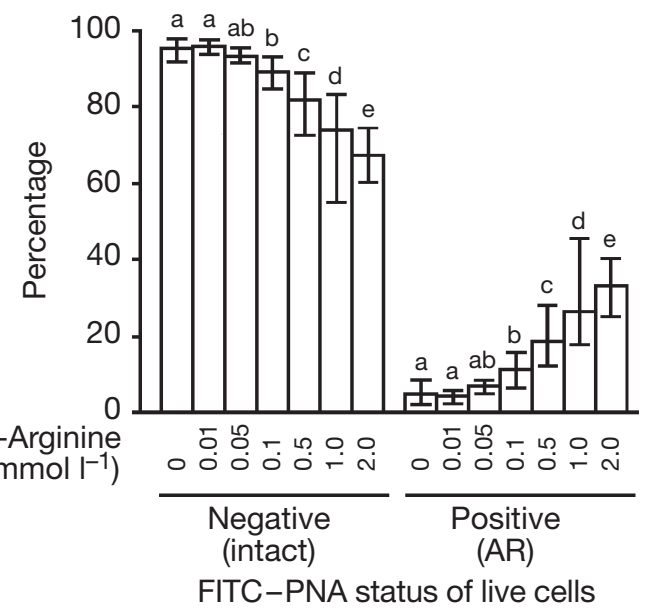

Fig. 1. The concentration-dependent effect of L-arginine on the (a) viability and (b) acrosome status of boar spermatozoa. Suspensions were cultured in the presence of $0-2$ mmol L-arginine $\mathrm{I}^{-1}$ in modified North Carolina State University medium 37 supplemented with 0.91 mmol sodium pyruvate ${ }^{-1}$ (mNCSU-37) for $2 \mathrm{~h}$ and assessed by propidium iodide (PI) and fluorescein isothiocyanate-peanut agglutinin (FITC-PNA) staining. Data are presented as mean percentage with ranges of cells expressing the different patterns in six replicate trials. Different letters above bars indicate significant differences within the same pattern $(P<0.05)$. AR: acrosome-reacted.

\section{Results}

\section{Induction of acrosome reaction by L-arginine}

The incidence of live spermatozoa was not different in suspensions treated with $0-0.5 \mathrm{mmol}$ L-arginine $\mathrm{I}^{-1}$, whereas there was a decrease in the percentage of live cells in suspension with 2 mmol L-arginine $\mathrm{I}^{-1}$ (Fig. 1a). The proportion of acrosome-intact live cells (no fluorescence) decreased in a dose-dependent manner even in the presence of only

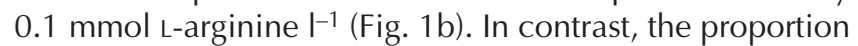
of acrosome-reacted live cells (FITC-PNA positive cells) increased in medium containing a higher concentration of L-arginine, although there were no differences among media

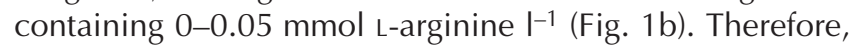

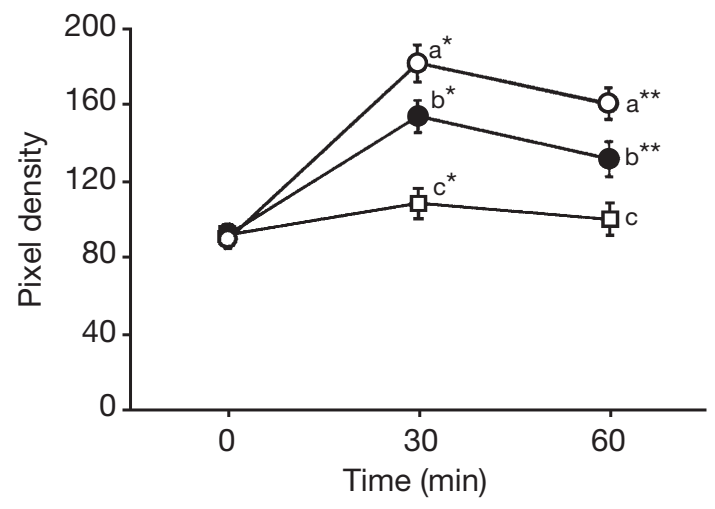

Fig. 2. Change of intracellular nitric oxide (NO) concentration of boar spermatozoa in the absence or presence of L-arginine. Fluorescence of boar spermatozoa loaded diaminofluorescein-2 diacetate (DAF-2 DA) was quantified at 0,30 and $60 \mathrm{~min}$ after exposure to $0(\square), 1(\bigcirc)$ and $2(\bigcirc)$ mmol L-arginine $\mathrm{I}^{-1}$ in modified North Carolina State University medium 37 supplemented with 0.91 mmol sodium pyruvate $\mathrm{I}^{-1}$ (mNCSU-37). Data are presented as mean pixel density \pm SEM of cells in three replicate trials. Different letters above bars indicate significant differences within the same observation time $(P<0.05)$. *Significant differences compared with $0 \mathrm{~min}(P<0.05)$. **Significant differences compared with 0 and $30 \min (P<0.05)$.

these data indicate that L-arginine induces acrosome reaction of ejaculated boar spermatozoa in $\mathrm{mNCSU}-37$.

\section{Effect of L-arginine expression through the synthesis of $\mathrm{NO}$}

Culture with L-arginine triggered a dose-dependent increase in DAF-2 fluorescence of spermatozoa at $60 \mathrm{~min}$ after the addition of L-arginine (Fig. 2). At $30 \mathrm{~min}$ after the start of culture, DAF-2 fluorescence significantly increased even in the absence of L-arginine. Between 30 and $60 \mathrm{~min}$ after the addition of L-arginine, DAF-2 fluorescence decreased in the

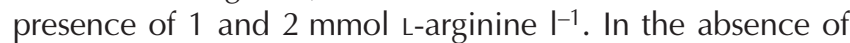
L-arginine, DAF-2 fluorescence at $60 \mathrm{~min}$ did not differ from that just before the addition of L-arginine $(0 \mathrm{~min})$. Therefore, these data indicate that L-arginine induces a dose-dependent increase in the NO content of spermatozoa.

The proportions of acrosome-reacted live cells decreased when $1 \mathrm{mmol}$ L-arginine $\mathrm{I}^{-1}$ plus various concentrations $\left(0.5,1.0\right.$ and $\left.2.0 \mathrm{mmol} \mathrm{I}^{-1}\right)$ of L-NAME were added, and the percentages of acrosome-reacted live cells in the presence of 1 or 2 mmol L-NAME I-1 were not different from that of control (no additives) (Fig. 3). However, supplementation with the inactive enantiomorph, D-NAME, did not affect the stimulatory effect of L-arginine. These data indicate that L-arginine induces acrosome reaction through the synthesis of NO.

\section{Induction of capacitation and acrosome reaction by $L$-arginine when anion exchanger is active}

Although the percentage of uncapacitated live (F-pattern) cells increased slightly in a medium containing caffeine 


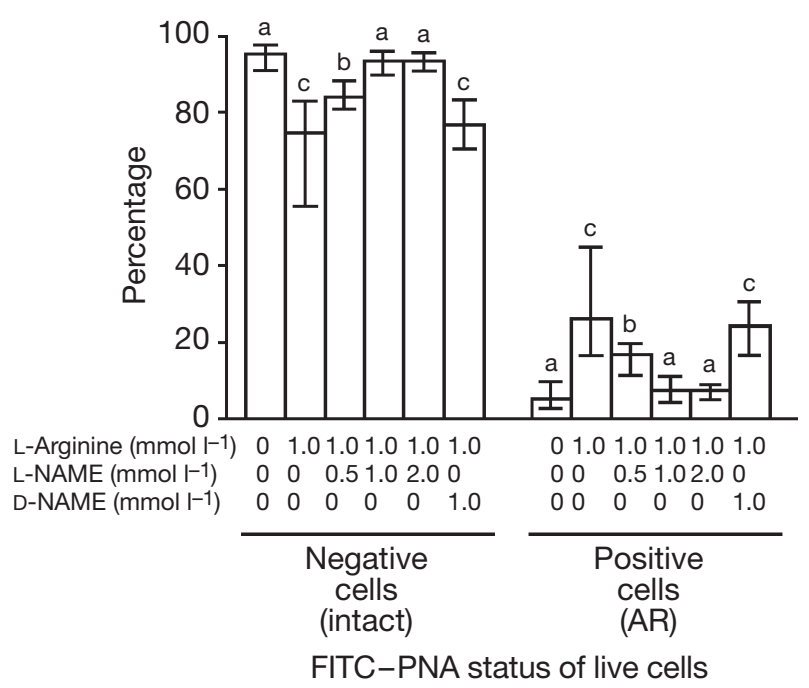

Fig. 3. Inhibitory effect of $\mathrm{N}^{\omega}{ }^{-}$-nitro-L-arginine methyl ester (L-NAME) on sperm response to L-arginine. Sperm suspensions were cultured in the presence or absence of $1 \mathrm{mmol} \mathrm{L}_{\text {-arginine }} \mathrm{I}^{-1}$

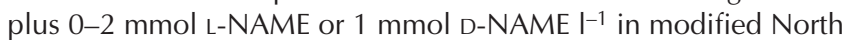
Carolina State University medium 37 supplemented with 0.91 mmol sodium pyruvate $\mathrm{I}^{-1}(\mathrm{mNCSU}-37)$ for $2 \mathrm{~h}$ and assessed by fluorescein isothiocyanate-peanut agglutinin (FITC-PNA) and propidium iodide $(\mathrm{PI})$ staining. Data are presented as mean percentage with ranges of cells expressing the different patterns in seven replicate trials. Different letters above bars indicate significant differences within the same pattern $(P<0.05)$. AR: acrosomereacted.

when SITS was added, the percentages of capacitated (B-pattern) and acrosome-reacted live cells were not affected by SITS, indicating that the response of spermatozoa to caffeine was not affected by SITS (Fig. 4). In contrast, the stimulatory effect of L-arginine on sperm capacitation was inhibited by SITS and the proportion of uncapacitated (F-pattern) live cells in media containing L-arginine plus SITS was not different from the control value. These results indicate that modification of anion transporter is associated with the induction of capacitation and acrosome reaction by L-arginine. When the location of anion transporter on the plasma membrane of boar spermatozoa was observed by detecting fluorescence from SITS, a strong fluorescence signal was detected in the post-acrosomal region of spermatozoa with a weak signal in the acrosomal region (data not shown).

\section{Requirement for endogenous bicarbonate for the stimulatory effect of L-arginine on capacitation}

When sperm samples were examined by means of FITCPNA and PI assessment, culture with L-arginine reduced the proportion of live spermatozoa that were acrosome-intact and increased the proportion of acrosome-reacted spermatoza in mNCSU37, whereas culture with L-NAME neutralized the stimulatory effect of L-arginine (Fig. 5). In contrast,

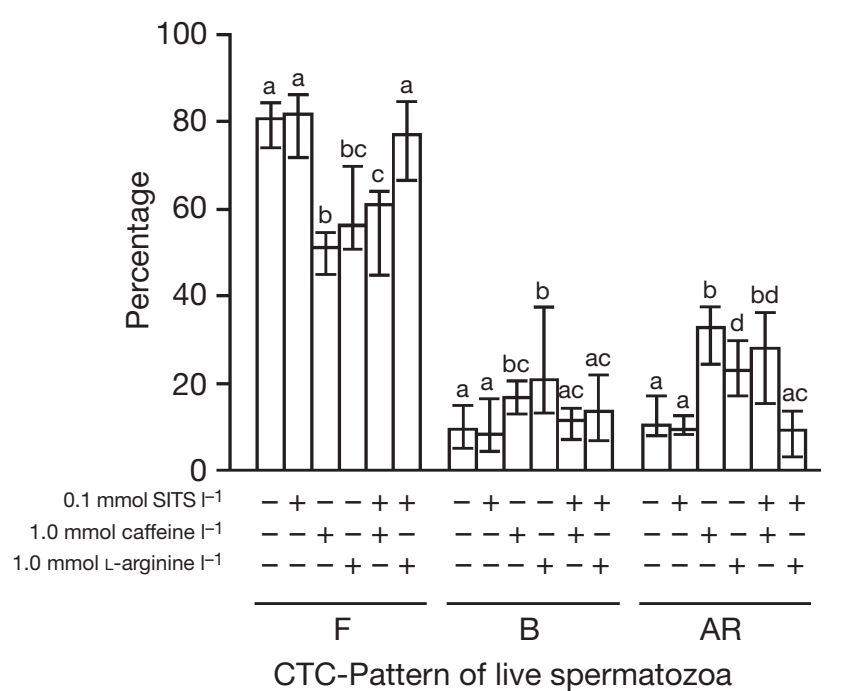

Fig. 4. Inhibitory effect of 4-acetamido-4'-isothiocyanostilbene2,2'-disulphonic acid (SITS) on response to L-arginine as determined by analysis of chlortetracycline fluorescence patterns of boar spermatozoa. Suspensions were cultured in the absence or presence of $0.1 \mathrm{mmol}$ SITS $\mathrm{I}^{-1}, 1.0 \mathrm{mmol}$ caffeine $\mathrm{I}^{-1}$ and/or $1.0 \mathrm{mmol}^{\mathrm{L}-a r g i n i n e} \mathrm{I}^{-1}$ in modified North Carolina State University medium 37 supplemented with 0.91 mmol sodium pyruvate $\mathrm{I}^{-1}$ (mNCSU-37) for $2 \mathrm{~h}$. Data are presented as mean percentage with ranges of cells expressing the different patterns in four to six replicate trials. Different letters above bars indicate significant differences within the same pattern $(P<0.05)$.

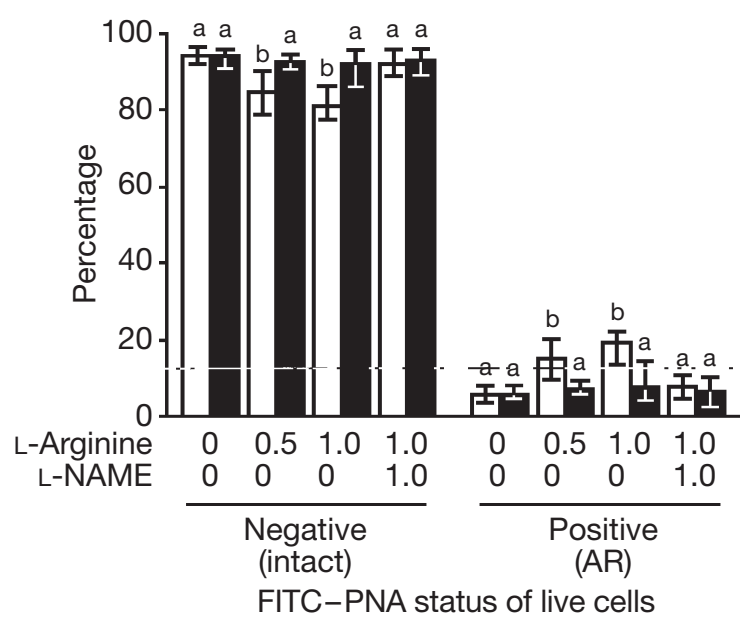

Fig. 5. Different responses of spermatozoa to L-arginine in a bicarbonate-buffered medium (mNCSU-37, $\square$ ) versus a Trisbuffered medium (mTBM, $\mathbf{\square}$ ) as determined by fluorescein isothiocyanate-peanut agglutinin (FITC-PNA) staining of boar spermatozoa. Sperm suspensions were cultured in the absence or presence of L-arginine $\left(0.5\right.$ and $\left.1.0 \mathrm{mmol} \mathrm{I}^{-1}\right)$, or $1 \mathrm{mmol} \mathrm{N}^{\omega^{\omega} \text {-nitro- }}$ L-arginine methyl ester (L-NAME) $\mathrm{I}^{-1}$ in $\mathrm{mNCSU}-37$ or mTBM for $2 \mathrm{~h}$. Data are presented as mean percentage with ranges of cells expressing the different patterns in four to eight replicate trials. Different letters above the bars indicate significant differences within the same fluorescence pattern $(P<0.05)$. AR: acrosomereacted. 


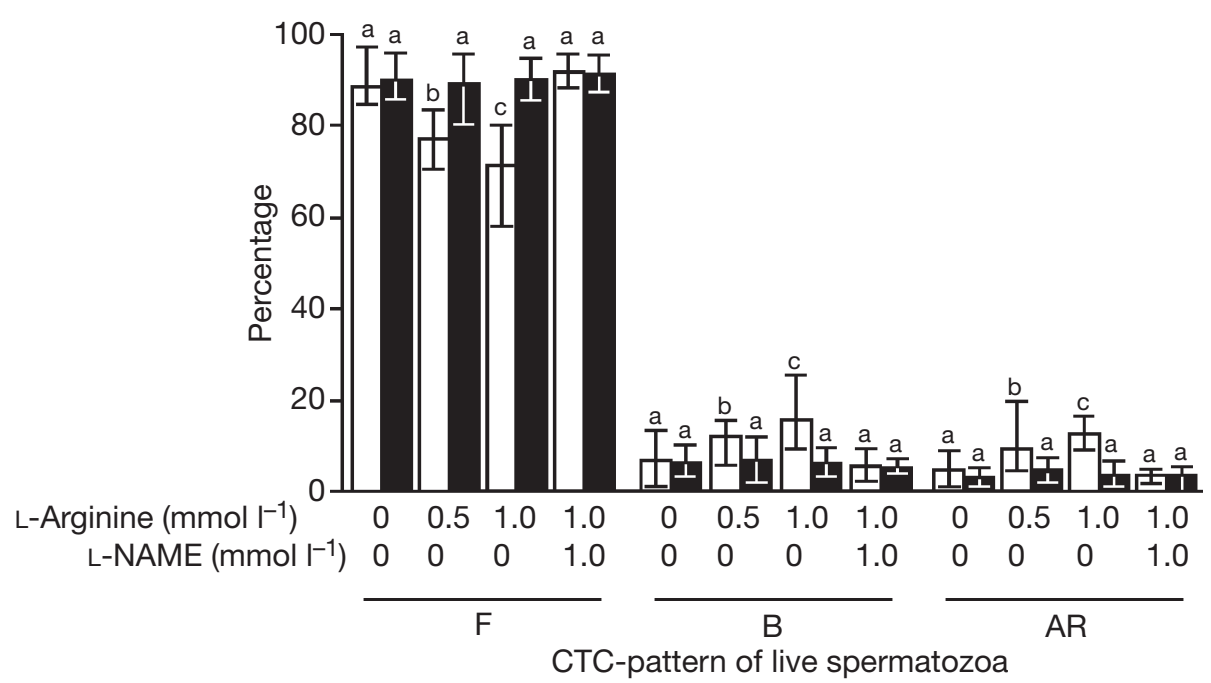

Fig. 6. Different responses of spermatozoa to L-arginine in a bicarbonate-buffered medium ( $\mathrm{mNCSU}-37, \square)$ versus a Tris-buffered medium (mTBM, $\mathbf{\square}$ ) as determined by analysis of chlortetracycline fluorescence patterns of boar spermatozoa. Sperm suspensions were cultured in the absence or presence of L-arginine $\left(0.5\right.$ and $\left.1.0 \mathrm{mmol} \mathrm{I}^{-1}\right)$, or $1 \mathrm{mmol} \mathrm{N}^{\omega}$-nitroL-arginine methyl ester (L-NAME) $\mathrm{I}^{-1}$ in $\mathrm{mNCSU}-37$ or mTBM for $2 \mathrm{~h}$. Data are presented as mean percentage with ranges of cells expressing the different patterns in nine replicate trials. Different letters above the bars indicate significant differences within the same pattern $(P<0.05)$.

any stimulatory effects of L-arginine were not observed in mTBM regardless of the presence of L-NAME. When spermatozoa were assessed by CTC fluorescence assay, culture with L-arginine again reduced the percentage of uncapacitated (F-pattern) cells and increased the percentage of capacitated (B-pattern) and acrosome-reacted (ARpattern) cells, whereas the effect of L-arginine was inhibited in the presence of L-NAME (Fig. 6). However, the presence of L-arginine did not affect the proportions of cells expressing any of the patterns of fluorescence when in mTBM.

\section{Discussion}

The present study demonstrated that L-arginine induces both $\mathrm{NO}$ synthesis and acrosome loss of boar spermatozoa in a bicarbonate- $\mathrm{CO}_{2}$-buffered medium, $\mathrm{mNCSU}-37$. The stimulatory effect of L-arginine on acrosome reaction was inhibited in a dose-dependent manner by an inhibitor of CNOS, L-NAME, but not by the inactive enantiomorph, D-NAME. These results are the first to indicate that ejaculated boar spermatozoa contain a cNOS activity and that the acrosome reaction induced by L-arginine in a bicarbonate-buffered medium occurs through the NO signal pathway. It has been reported that concentrations of L-arginine in the oviductal fluid of oestrous sows and rabbits were $3.72 \pm 1.25 \mathrm{mg}(100 \mathrm{ml})^{-1}\left(0.214 \pm 0.072 \mathrm{mmol} \mathrm{I}^{-1}\right)$ and $2.62 \pm 0.60 \mathrm{mg}(100 \mathrm{ml})^{-1}\left(0.150 \pm 0.034 \mathrm{mmol} \mathrm{l}^{-1}\right)$, respectively (Engle et al., 1968). Similar concentrations of L-arginine have also been detected in the oviductal fluid of oestrous ewes $\left(2.14 \mathrm{mg}\left(100 \mathrm{ml}^{-1} ; 0.123 \mathrm{mmol}^{-1}\right)\right.$ (Perkins and Goode, 1967) and humans (0.19 $\left.\mathrm{mmol} \mathrm{I}^{-1}\right)$ (Tay et al.,
1997). The results of the present study indicate that L-arginine promoted acrosome reaction of boar spermatozoa even at $0.1 \mathrm{mmol} \mathrm{I}^{-1}$, indicating that L-arginine in the oviductal fluid has a minimal physiological role on spermatozoa in the oviduct.

The results of the present study indicate that the viability of boar spermatozoa was not affected even in $0.01-1.0 \mathrm{mmol}$ L-arginine $\mathrm{I}^{-1}$ and that acrosome exocytosis of the spermatozoa was stimulated at $0.1-2.0 \mathrm{mmol} \mathrm{I}^{-1}$. The results from the CTC analysis in the present study also demonstrated that L-arginine at concentrations examined $(0.5$ and $1.0 \mathrm{mmol}$ $\left.\mathrm{I}^{-1}\right)$ stimulated both capacitation and acrosome reaction of boar spermatozoa. Therefore, an increased intracellular NO content of boar spermatozoa stimulated by L-arginine (up to $1 \mathrm{mmol} \mathrm{I}^{-1}$ ) appears to induce capacitation and acrosome loss of the cells without any reduction in viability. This result could be supported by evidence that sperm penetration in vitro has been achieved in pigs in modified Medium199 , which originally contained $0.33 \mathrm{mmol} \mathrm{L}^{-}$arginine $\mathrm{I}^{-1}$ (for reviews, see Funahashi and Day, 1997; Abeydeera, 2001). Interestingly, even supplementation of modified Medium-199 containing 0.4\% BSA with $1 \mathrm{mmol}$ L-arginine $\mathrm{I}^{-1}$ results in an increased incidence of acrosome reaction of boar spermatozoa, without any reduction in viability (H. Funahashi, unpublished).

Furthermore, the present study assessed by means of FITC-PNA staining and CTC fluorescence assay showed that L-arginine induced both capacitation and acrosome reaction in a bicarbonate- $\mathrm{CO}_{2}$-buffered medium, but not in a supplemented bicarbonate-free Tris-buffered medium. Bicarbonate is known to induce capacitation and penetra- 
tion of boar spermatozoa in vitro (Suzuki et al., 1994; Harrison 1996; Harrison et al., 1996), via protein kinase A-dependent changes in the plasma membrane (Gadella and Harrison, 2000). Under a $\mathrm{CO}_{2}$-containing atmosphere, $\mathrm{CO}_{2}$ dissolved in medium will be converted to carbonic acid and then to dissociated bicarbonate ion and $\mathrm{H}^{+}$ (Umbreit, 1957). The precise concentration of bicarbonate ion will depend on the buffer composition and its $\mathrm{pH}$. In bicarbonate-free Hepes-buffered modified Tyrodes' medium, which was not equilibrated in an atmosphere of $5 \% \mathrm{CO}_{2}$ in air, no sperm penetration occurred in pig oocytes even in the presence of caffeine (Suzuki et al., 1994). Bicarbonate ion derived from only $\mathrm{CO}_{2}$ dissolved in caffeine-free media may not be sufficient to induce efficient capacitation and the acrosome reaction of boar spermatozoa via the L-arginine-NO pathway. Additional supplementation with bicarbonate increases the incidence of sperm penetration into pig oocytes in the presence of caffeine in an atmosphere of $5 \% \mathrm{CO}_{2}$ in air (Wang et al., 1995; Abeydeera et al., 1997). Therefore, the results of the present study indicate that supplementation with bicarbonate appears to be required for the induction of capacitation and acrosome reaction of boar spermatozoa by the L-arginine-NO pathway.

The present study demonstrates that the response of boar spermatozoa to L-arginine was markedly inhibited in the presence of SITS in a bicarbonate- $\mathrm{CO}_{2}$-buffered medium. An anion transport inhibitor, SITS, reversibly inhibited the bicarbonate-sensitive adenylyl cyclase in the plasma membrane of boar spermatozoa (Okamura et al., 1991) and prevented the acrosome reaction of bull (Spira and Breitbart, 1992) and hamster spermatozoa (Visconti et al., 1999) in the bicarbonate-containing medium. However, in general, bicarbonate can pass rather freely across membranes via interconversion with $\mathrm{CO}_{2}$, which is highly permeable, and the bicarbonate-chloride exchanger acts to externalize the bicarbonate ion (Madshus, 1988). Anion channel blockers, phosphotungstate and 4,4'-diisothiocyanatostilbene-2,2'-disulphonate, enhanced bicarbonateinduced activation in the motility, respiration rate and the cAMP content of boar epididymal spermatozoa because its efflux of endogenous bicarbonate ion derived from metabolic $\mathrm{CO}_{2}$ was inhibited and thence because bicarbonate ion was accumulated intracellularly (Tajima and Okamura, 1990). SITS, which is impermeable and acts by binding to the membrane band-3 polypeptides, is known as an inhibitor of anion transporters, not specific to the bicarbonate-chloride transporter (Cabantchik et al., 1978). It is known that $\mathrm{NO}$ donors stimulate ion transport in human colonic muscle cells in vitro (Stack et al., 1996). In the present study, the anion exchanger, detected by the fluorescence of SITS, on the plasma membrane of boar spermatozoa was detected mainly in the post-acrosomal region. Endothelial NOS activity was also evident in the post-acrosomal and equatorial regions of morphologically normal human spermatozoa (O'Bryan et al., 1998). Therefore, these reports and results of the present study indicate that active anion transport, at least without bicarbonate-chloride exchanger, appears to be highly associated with the L-arginine-NO pathway to induce capacitation-acrosome reaction of boar spermatozoa. However, it is still unclear how the entrance of a cationic amino acid, such as L-arginine, is affected by the inhibition of anion transport by SITS in the present study.

The addition of dibutyryl cAMP has been known to induce the acrosome reaction in bicarbonate-free medium (Visconti et al., 1999) and partially to reverse the inhibition of the acrosome reaction induced by SITS (Spira and Breitbart, 1992; Visconti et al., 1999). These data and the results from the present study indicate that NO may be contained in the bicarbonate-sensitive cAMP-adenylyl cyclase signal pathway via active anion transport to induce capacitation and acrosome reaction of boar spermatozoa. Herrero et al. (2000) suggested that NO acts as a cellular messenger by modulating the CAMP pathway involved in capacitation and protein tyrosine phosphorylation. However, an NO donor, sodium nitroprusside was demonstrated to increase the percentage of acrosome reaction in capacitated human spermatozoa via stimulation of an NO-sensitive sCG, cGMP synthesis and protein kinase G activation (Revelli et al., 2001). This effect appears to involve the activation of protein kinase $C$ in the presence of extracellular calcium ion (Revelli et al., 2001). An increase in intracellular cGMP has also been observed during NOdependent stimulation of acrosome reaction in capacitated bull spermatozoa. Since a growing number of experimental results indicate that $\mathrm{NO}$ can induce its biological effect via pathways that are not cGMP-dependent, the target of $\mathrm{NO}$ on capacitation and acrosome reaction of boar spermatozoa may not be only cGMP-dependent pathways. Further studies are required to clarify the mechanism of the L-arginine-NO signal pathway.

In conclusion, the results of the present study demonstrate that L-arginine induces the capacitation and acrosome reaction of ejaculated boar spermatozoa through the $\mathrm{NO}$ signal pathway. Experiments using an anion transport inhibitor in different culture media showed that an active anion exchanger and supplementation with bicarbonate are required for the L-arginine-NO pathway.

The author would like to thank B. N. Day of the University of Missouri-Columbia for a critical read and suggestions. The author would also like to thank Okayama Prefectural Center for Animal Husbandry and Research for supplying fresh boar semen.

\section{References}

Abeydeera LR (2001) In vitro fertilization and embryo development in pigs Reproduction Supplement 58 159-173

Abeydeera LR, Funahashi H, Kim NH and Day BN (1997) Chlortetracycline fluorescence patterns and in vitro fertilisation of frozen-thawed boar spermatozoa incubated under various bicarbonate concentrations Zygote 5 117-125

Burnett AL, Lowenstein CJ, Bredt DS, Chang TSK and Snyder SH (1992) Nitric oxide: a physiological mediator of penile erection Science $\mathbf{2 5 7}$ 401-403 
Burnett AL, Ricker DD, Chamness SL, Maguire MP, Crone JK, Bredt DS, Snyder SH and Chang TSK (1995) Localization of nitric oxide synthase in the reproductive organs of the male rat Biology of Reproduction 52 1-7

Cabantchik ZI, Knauf PA and Rothstein A (1978) The anion transport system of the red blood cell Biochimica et Biophysica Acta 515 239-302

de Lamirande E, Jiang H, Zini A, Kodama H and Gagnon C (1997) Reactive oxygen species and sperm physiology Reviews of Reproduction 2 48-54

Engle CC, Dunn JS, Hood RD, Williams DJI, Foley CW and Trout HF (1968) Amino acids in sow and rabbit oviduct fluids Journal of Animal Science 271786 (Abstract)

Fazeli A, Hage WJ, Cheng FP, Voorhout WF, Marks A, Bevers MM and Colenbrander B (1997) Acrosome-intact boar spermatozoa initiate binding to the homologous zona pellucida in vitro. Biology of Reproduction 56 430-438

Funahashi H and Day BN (1997) Advances in in vitro production of pig embryos Journal of Reproduction and Fertility Supplement 52 271-283

Funahashi H and Nagai T (2001) Regulation of in vitro penetration of frozen-thawed boar spermatozoa by caffeine and adenosine Molecular Reproduction and Development 58 424-431

Funahashi H, Cantley TC and Day BN (1997) Synchronization of meiosis in porcine oocytes by exposure to dibutyryl cyclic AMP improves developmental competence following in vitro fertilization Biology of Reproduction 57 49-53

Funahashi H, Fujiwara T and Nagai T (2000) Modulation of the function of boar spermatozoa via adenosine and fertilization promoting peptide receptors reduce the incidence of polyspermic penetration into porcine oocytes Biology of Reproduction 63 1157-1163

Gadella BM and Harrison RA (2000) The capacitating agent bicarbonate induces protein kinase A-dependent changes in phospholipid transbilayer behavior in the sperm plasma membrane Development 127 2407-2420

Guzman-Grenfell AM, Hernandez SR, Gonzalez-Martinez MT and Hicks JJ (1999) Effect of nitric oxide releasers on some metabolic processes of rabbit spermatozoa Archives of Andrology 42 119-123

Harrison RA (1996) Capacitation mechanisms, and the role of capacitation as seen in eutherian mammals Reproduction, Fertility and Development 8 581-594

Harrison RAP, Ashworth PJC and Miller NGA (1996) Bicarbonate/CO, an effector of capacitation, induces a rapid and reversible change in the lipid architecture of boar sperm plasma membranes Molecular Reproduction and Development 45 378-391

Herrero MB, Perez-Martinez S, Viggiano JM, Polak JM and Gimeno MF (1996) Localization by indirect immunofluorescence of nitric oxide synthase in mouse and human spermatozoa Reproduction, Fertility and Development 8 931-934

Herrero MB, Goin JC, Boquet M, Canteros MG, Franchi AM, PerezMartinez S, Polak JM, Viggiano JM and Gimeno MAF (1997a) The nitric oxide synthase of mouse spermatozoa FEBS letters 411 39-42

Herrero MB, Viggiano JM, Perez Martinez S and de Gimeno MF (1997b) Evidence that nitric oxide synthase is involved in progesterone-induced acrosomal exocytosis in mouse spermatozoa Reproduction, Fertility and Development 9 433-439

Herrero MB, de Lamirande E and Gagnon C (1999) Nitric oxide regulates human sperm capacitation and protein-tyrosine phosphorylation in vitro. Biology of Reproduction 61 575-581

Herrero MB, Chatterjee S, Lefievre L, de Lamirande E and Gagnon C (2000) Nitric oxide interacts with the CAMP pathway to modulate capacitation of human spermatozoa Free Radical Biology and Medicine 29 522-536

Joo BS, Park SH, Park SJ, Kang HS, Moon HS and Kim HD (1999) The effect of nitric oxide on sperm cell function and embryo development American Journal of Reproductive Immunology (Copenhagen) 42 327-334

Keller DW and Polakoski KL (1975) L-arginine stimulation of human sperm motility in vitro. Biology of Reproduction 13 154-157

Lewis SEM, Donnelly ET, Sterling ESL, Kennedy MS, Thompson W and Chakravarthy $\mathbf{U}(1996)$ Nitric oxide synthase and nitrite production in human spermatozoa: evidence that endogenous nitric oxide is beneficial to sperm motility Molecular Human Reproduction 2 873-878
Madshus IH (1988) Regulation of intrecellular $\mathrm{pH}$ in eukaryotic cells Biochemical Journal 250 1-8

O'Bryan MK, Zini A, Cheng CY and Schlegel PN (1998) Human sperm endothelial nitric oxide synthase expression: correlation with sperm motility Fertility and Sterility 70 1143-1147

Okamura N, Tajima Y, Onoe S and Sugita Y (1991) Purification of bicarbonate-sensitive sperm adenylylcyclase by 4 -acetamido-4' isothiocyanostilbene-2,2'-disuffonic acid-affinity chromatography Journal of Biological Chemistry 26617 754-17 759

Palmer RMJ and Moncada S (1989) A novel citrulline-forming enzyme implicated in the formation of nitric oxide by vascular endothelial cells Biochemica Biophysica Research Communications 158 348-352

Palmer RMJ, Ashton DS and Moncada S (1988) Vascular endothelial cells synthesize nitric oxide from L-arginine Nature 333 664-666

Perkins JL and Goode L (1967) Free amino acids in the oviduct fluid of the ewe Journal of Reproduction and Fertility 14 309-311

Randany EW and Atherton RW (1981) Arginine induced stimulation of rabbit sperm motility Archives of Andrology 7 351-355

Revelli A, Soldati G, Costamagna C, Pellerey O, Aldieri E, Massobrio M, Bosia A and Ghigo D (1999) Follicular fluid proteins stimulate nitric oxide (NO) synthesis in human sperm: a possible role for $\mathrm{NO}$ in acrosome reaction Journal of Cellular Physiology 178 85-92

Revelli A, Costamagna C, Moffa F, Aldieri E, Ochetti S, Bosia A, Massobrio M, Lindblom B and Ghigo D (2001) Signaling pathway of nitric oxideinduced acrosome reaction in human spermatozoa Biology of Reproduction 64 1708-1712

Sengoku K, Tamate K, Yoshida T, Takaoka Y, Miyamoto T and Ishikawa M (1998) Effects of low concentrations of nitric oxide on the zona pellucida binding ability of human spermatozoa Fertility and Sterility 69 522-527

Spira B and Breitbart $\mathbf{H}$ (1992) The role of anion channels in the mechanism of acrosome reaction in bull spermatozoa Biochemica et Biophysica Acta 1109 65-73

Stack WA, Filipowicz B and Hawkey CJ (1996) Nitric oxide donating compounds stimulate human colonic ion transport in vitro. Gut 39 93-99

Suzuki K, Ebihara M, Nagai T, Clarke NGE and Harrison RAP (1994) Importance of bicarbonate/ $\mathrm{CO}_{2}$ for fertilization of pig oocytes in vitro, and synergism with caffeine Reproduction, Fertility and Development 6 $221-227$

Tajima $\mathbf{Y}$ and Okamura $\mathbf{N}$ (1990) The enhancing effects of anion channel blockers on sperm activation by bicarbonate Biochimica et Biophysica Acta 1034 326-332

Tay JI, Rutherford AJ, Killick SR, Maquiness SD, Partridge RJ and Leese HJ (1997) Human tubal fluid: production, nutrient composition and response to adrenergic agents Human Reproduction 12 2451-2456

Umbreit WW (1957) Carbon dioxide and bicarbonate. In Manometric Techniques 3rd Edn. pp 18-27 Eds WW Umbreit, RH Burris and JF Stauffer. Burgess Pub. Co., Minneapolis

Viggiano JM, Herrero MB, Martinez SP and De Gimeno MF (1996) Analysis of the effect of nitric oxide synthase inhibition on mouse sperm employing a modified staining method for assessment of the acrosome reaction Journal of Andrology 17 692-698

Visconti PE, Stewart-Savage J, Blasco A, Battaglia L, Miranda P, Kopf GS and Tezon JG (1999) Roles of bicarbonate, cAMP and protein tyrosine phosphorylation on capacitation and the spontaneous acrosome reaction of hamster sperm Biology of Reproduction 61 76-84

Wang WH, Abeydeera LR, Fraser LR and Niwa K (1995) Functional analysis using chlortetracycline fluorescence and in vitro fertilization of frozen-thawed ejaculated boar spermatozoa incubated in a protein-free chemically defined medium Journal of Reproduction and Fertility 104 305-313

Received 4 April 2002.

First decision 23 July 2002.

Revised manuscript received 27 August 2002.

Accepted 16 September 2002. 